\title{
INFLUÊNCIA DOS ASPECTOS REGIONAIS E LOCAIS NO CONSUMO DE WEB RÁDIO, NO MUNICÍPIO DE DOURADOS (MS)
}

INFLUENCE OF REGIONAL AND LOCAL ASPECTS ON WEB RADIO CONSUMPTION, IN DOURADOS (MS)

\author{
Daniela Cristiane OTA ${ }^{1}$ \\ Aline de Oliveira SILVA² \\ Universidade Federal de Mato Grosso do Sul | Brasil
}

\begin{abstract}
Resumo
O município de Dourados, localizado na região Sul de Mato Grosso do Sul é o segundo colocado em número de habitantes e registra o terceiro maior Produto Interno Bruto (PIB) do estado. Com 84 anos de emancipação política e 220 mil habitantes registra um cenário midiático diversificado e com uma característica marcante. $O$ número de web rádios em funcionamento soma 35 contra 11 emissoras de Amplitude Modulada (AM) e Frequência Modulada (FM). Com intuito de identificar o perfil das rádios digitais foi realizada uma pesquisa exploratória em fevereiro de 2020, a qual identificou os gêneros radiofônicos mais utilizados que são: entretenimento, publicitário e jornalístico.

Palavras-chave

Rádio; Web Rádio; Gêneros radiofônicos; Analógico ao digital; Regionalidade.

Abstract

The municipality of Dourados, located in the southern region of Mato Grosso do Sul is the second largest in number of inhabitants and registers the third largest Gross Domestic Product (GDP) in the state. With 84 years of political emancipation and 220 thousand inhabitants, it registers a diversified media scene and with a remarkable characteristic. The number of web radios in operation adds up to 35 against 11 Modulated Amplitude (AM) and Modulated Frequency (FM) stations. In order to identify the profile of digital radio, an exploratory research was carried out in February 2020, which identified the most used radio genres which are: entertainment, advertising and journalism.

Keywords

Radio; Web radio; Radio genres; Analog to digital; Regionality.
\end{abstract}

RECEBIDO EM 23 DE MARÇO DE 2020

ACEITO EM 11 DE MAIO DE 2020

\footnotetext{
1 Pós-doutora e Docente do Curso de Jornalismo e do programa de Mestrado em Comunicação da Universidade Federal de Mato Grosso do Sul - UFMS. Orientadora do trabalho. Contato: daniela.ota@ufms.br.

2 Mestranda do programa de Mestrado em Comunicação da Universidade Federal de Mato Grosso do Sul - UFMS. Contato: alineolsilva@hotmail.com.
}

João Pessoa - Brasil | ANO 7 VOL.7 N.1 | JAN./JUN. 2020 | p. 263-279 


\section{ÂCORA}

Daniela Cristiane OTA - Aline de Oliveira SILVA

\section{Introdução}

rádio completa o centenário de existência no Brasil com
transformações inimagináveis há algumas décadas passadas. o
surgimento da concorrente televisão e posteriormente, da internet provocaram anúncios apocalípticos da "morte" do veículo que até os dias atuais mantém sua audiência e ouvintes, em todas regiões do território nacional.

Contudo, várias mudanças tecnológicas foram importantes para sua permanência entre os veículos de comunicação de massa, entre elas a implantação e funcionamento das web rádios, que surgiram com a proposta de segmentar a programação, ou conforme o dito popular, 'atender o gosto do cliente'.

A rapidez com que a plataforma digital evoluiu para todos os cantos do globo pode ser observada pelo exemplo norte-americano, no qual as primeiras experiências com o rádio digital foram datadas a partir de 1990, passando pelo início na transmissão da primeira emissora (Rádio KLIF, no Texas, em 1995) até chegar ao Brasil dois anos depois (1997). Com essa perspectiva buscou-se elencar alguns dos principais momentos do rádio, a fim de traçar uma linha temporal que culminou na implantação das web rádios no País.

A apresentação da formação territorial de Dourados teve objetivo de contextualizar a realidade local e regional, apresentando as particularidades dos povos nativos e de outros estados e países que se estabeleceram no local, contribuindo para consolidação da identidade cultural, social e econômica da região.

O próximo passo foi detalhar a história da comunicação em rádio no município que somente a partir de 1955 contou com a transmissão radiofônica, por intermédio da Rádio Clube Dourados. Em pouco mais de seis décadas, 0 crescimento no número de emissoras demonstrou a preferência dos ouvintes pelo meio, e ainda, fez surgir um público interessado em consumir 
programações produzidas e disponibilizadas exclusivamente em plataformas digitais.

É válido ressaltar que a reconfiguração do conteúdo para o ambiente digital não modificou expressivamente a linha editorial das rádios que continuam a oferecer produções locais e regionais, atendendo demandas específicas do público (onde o estilo musical predominante é o sertanejo e o radiojornalismo mantém as características das rádios AM e FM).

A afirmação é referendada pelo resultado de uma pesquisa realizada no mês de fevereiro de 2019 e atualizada no mesmo período, em 2020. Foi identificada inicialmente a existência de 18 web rádios, número que aumentou para 35 no intervalo de um ano. A evolução no número de veículos reforçou o interesse da investigação, a fim de compreender a dinâmica do fluxo radiofônico na localidade e ainda, identificar qual o perfil programático desses canais.

O estudo inicial contribuiu para o trabalho de dissertação de mestrado de uma das autoras que desenvolveu uma pesquisa sobre o radiojornalismo rural no município sul-mato-grossense. Dessa forma, o cenário identificado colabora ainda, para o aprofundamento dos estudos de rádio no âmbito das plataformas digitais, como é o caso da Web Rádio. Na atualidade, um dos maiores desafios dos pesquisadores é conceituar e explicar a rápida transformação do meio que migrou do sistema analógico para o digital e os fatores sociais, econômicos e culturais atrelados ao processo.

Optou-se por utilizar a definição de gêneros radiofônicos proposta pelo pesquisador André Barbosa Filho, identificando assim as categorias jornalísticas, de entretenimento e publicitária. Os resultados iniciais oferecem assim, material vasto para futuros desdobramentos que podem incluir estudos de recepção e audiência entre o público consumidor de rádio digital na região. 


\section{ANCORA}

Daniela Cristiane OTA - Aline de Oliveira SILVA

\section{Rádio em transformação}

As pesquisas sobre o surgimento do veículo rádio no Brasil e sua evolução até a atualidade comprovam que as principais características: oralidade, penetração, mobilidade, baixo custo, imediatismo, instantaneidade, sensorialidade e autonomia, detalhados por Ortiwano (1985), foram responsáveis pela sobrevivência e adaptação do meio, quanto à chegada dos concorrentes diretos, televisão e internet.

A inauguração oficial aconteceu em 7 de setembro de 1922, contudo, Sampaio (1971) esclarece que a primeira transmissão foi registrada no dia 6 de abril de 1919, por intermédio da Rádio Clube de Pernambuco, na cidade de Recife. Ainda que exista esse hiato de três anos, o veículo completa seu centenário no Brasil e se destaca por ter contribuído com a disseminação da informação na perspectiva territorial, seja ela noticiosa, cultural e de entretenimento.

Com o início da primeira gestão do ex-presidente Getúlio Vargas (19301934) houve forte estímulo para que a sociedade tivesse acesso à informação radiofônica e para tal, o governo sugeria que os estados e municípios instalassem rádios-receptores munidos de alto falantes. Na avaliação de Haussen (2004), é certo que o gestor público tinha interesse em impor seu projeto político, baseado na unificação nacional e influenciado pelo ministério da propaganda na Alemanha. Tanto é verdade que com o desenvolvimento tecnológico desencadeado no país, testemunhou-se o surgimento e disseminação de inúmeras emissoras nas décadas seguintes.

Entretanto, é a partir da década de 1940 que o veículo registraria outro momento importante e que impulsionou o desenvolvimento do radiojornalismo brasileiro. Moreira (2011) reforça que a primeira edição do informativo "Repórter Esso", transmitido em ondas médias e curtas pela Rádio Nacional do Rio de Janeiro, em 28 de agosto de 1941 trouxe importantes contribuições para o modelo radiofônico, das quais o noticiário com linguagem própria para 
rádio. "Frases curtas, elaboradas em ordem direta, números escritos por extenso, a voz, intérprete do fato, que fez de Heron Domingues exemplo a ser seguido pelos locutores". (MOREIRA, 2011, p. 10).

Perspectiva relevante foi analisada por Ortriwano (1985), ao afirmar que entre os meios de comunicação de massa, o rádio é o mais popular e de maior alcance público, não só no Brasil como em todo mundo. "Constituindo-se muitas vezes, no único a levar informação para populações que não têm acesso a outros meios, seja por motivos geográficos, econômicos ou culturais". (ORTRIWANO, 1985, p. 79).

Após quase quatro décadas da afirmação feita pela pesquisadora é confirmada a condição de mobilidade do meio, ampliada ainda mais por sua reconfiguração e presença no espaço virtual. Corroborando com o atual momento da informação, Meditsch (2007) pontua que o rádio tem condições de explorar as contradições internas do sistema global e oferecer mais diversidade de informação e entretenimento. "Os equipamentos necessários estão ao alcance de qualquer comunidade e as FM cortam quarteirões, bairros, cidade e o campo" (MEDITSCH, 2007, p. 19).

Ferrareto (2014) esclarece que as transformações realizadas entre as décadas de 1990 e 2000 - com a implantação da internet, telefonia celular e aparelhos eletrônicos que possibilitaram novos acessos à programação radiofônica - impuseram a necessidade de uma revisão conceitual nos termos do rádio e de suas particularidades.

Além de uma lógica de oferta, o rádio passa a incluir uma lógica de demanda, presente, por exemplo, na disponibilização via internet de áudios de material já transmitido (...). Ocorrem manifestações não só relacionadas ao modelo de comunicação ponto-massa, o das irradiações em tempo real, mas ponto-ponto, próprio dos conteúdos disponibilizados de forma diferida por exemplo, por podcasting (FERRARETO, 2014, p. 17).

A fim de pontuar a importância da reformulação sobre o que significa o meio rádio é fundamental destacar a análise de Meditsch (2013, p. 204), na 


\section{ÂNEORA}

Daniela Cristiane OTA - Aline de Oliveira SILVA

qual sugere pensar o rádio como uma instituição social. "O rádio como instituição não pode mais ser atrelado à natureza dos equipamentos de transmissão, mas, sim à especificidade do fluxo sonoro que proporciona e às relações socioculturais que estabelece".

$\mathrm{O}$ argumento do docente contribui para o entendimento da realidade atual do meio em cenário nacional, visto que o consumo, a preferência e o perfil do ouvinte estão diretamente atrelados à região aonde mora, a faixa etária, classe social e forma de acessar o conteúdo sonoro. Pode-se acrescentar a essas variáveis, a análise da audiência dos programas, que também poderão mudar de acordo com as particularidades culturais, sociais e econômicas.

No tocante a evolução do rádio e a convergência dos meios de comunicação de massa para o formato multimídia, destaca-se a avaliação da pesquisadora Sonia Virgínia Moreira (2001), na qual esclarece que as fases iniciais de todas as novas tecnologias são marcadas por fatores econômicos, visto que a realidade é diferente para os países desenvolvidos e as nações em desenvolvimento.

Nesta perspectiva é oportuno lembrar o tamanho e preço do aparelho na chegada ao Brasil, que ao longo das décadas foi se compactando até alcançar as diversas opções da atualidade, contempladas por equipamentos como o smartphone, por exemplo. "A multiplicação de acesso aos novos meios é uma tendência mundial, com a perspectiva de redução no preço dos equipamentos de informática e dos serviços de telecomunicações". (MOREIRA, 2001, p. 22).

Desde as considerações feitas há 19 anos, novos formatos e tecnologias surgiram, contudo, um ponto considerado pela pesquisadora continua atual e requer dos pesquisadores uma atenção mais aprofundada. "Mesmo com as facilidades disponíveis na internet ou nas transmissões de áudio digital, o perfil 
dos ouvintes tende a continuar local, ainda que com uma inserção global". (MOREIRA, 2001, p. 23).

\section{Do Analógico ao Digital}

Em termos de transformação digital, os Estados Unidos foi um dos países pioneiros em implementar a mudança do rádio para o ambiente virtual, em meados da década de 1990 (Kuhn, 2000). Nesse sentido, a motivação das emissoras nacionais surgiu do interesse em ampliar a transmissão radiofônica via satélite, por intermédio do sistema denominado Digital Audio Broadcasting. As experiências positivas resultaram, cinco anos depois, no início da transmissão da rádio KLIF de Dallas, no estado do Texas, considerada a primeira emissora comercial a transmitir a programação ao vivo via internet.

No Brasil, a primeira rádio brasileira reconhecida por operar exclusivamente no ambiente virtual foi a Rádio Totem, em 1998. No entanto, a primeira experiência citada por alguns pesquisadores diz respeito ao programa Manguetronic veiculado em 1996 por dois integrantes do movimento Mangue Beat ${ }^{3}$, H.D. Mabuse e Renato L. (ITINOSI, 1997). No mesmo período, várias rádios iniciaram a migração para a rede, entre elas, a Rádio Itatiaia de Minas Gerais "que reivindica a primazia de ter sido a primeira a veicular seu sinal também pela internet". (TRIGO-DE-SOUZA, 2003, p. 96).

A consolidação da internet e o surgimento das plataformas digitais reestruturaram a dinâmica do meio ocasionando novas formas de interação entre ouvintes e emissoras, ou ainda entre os próprios ouvintes, conforme ressalta o pesquisador Marcelo Kischinhevsky (2016). No entanto, o docente acrescenta que no âmbito dos conteúdos, "persistem formatos e gêneros consolidados na programação das emissoras de rádio desde os anos 1980, tais como informativos, esportivos e shows de variedade". (KISCHINHEVSKY, 2016, p. 55).

${ }^{3}$ Movimento cultural criado em Recife (PE) que teve na música sua maior expressão com Chico Science e Nação Zumbi.

João Pessoa - Brasil | ANO 7 VOL.7 N.1 | JAN./JUN. 2020 | p. 263-279 


\section{ANTEORA}

Daniela Cristiane OTA - Aline de Oliveira SILVA

Com relação à pesquisa apresentada, a qual tem objetivo de traçar um perfil das web rádios localizadas no município de Dourados, é possível observar uma condição peculiar entre as emissoras em atividade. Em primeiro lugar porque o número das rádios digitais soma 35 portais, conforme levantamento atualizado em fevereiro de 2020, contra 11 veículos que operam em Amplitude Modulada (AM) e Frequência Modulada (FM). Em seguida ao se realizar uma categorização inicial sobre a programação ficou comprovado que a maioria do conteúdo está focado em música e religião.

É oportuno destacar que do total de rádios digitais elencadas, somente duas apresentam conteúdo jornalístico, enquanto que 10 informam disponibilizar conteúdo 'eclético' (mescla extensa programação musical intercalada com boletins e notas reproduzidas dos sites jornalísticos locais e regionais). Observa-se deste modo, uma heterogeneidade na categorização dos veículos que se alinha com as características do município.

Dourados registra 84 anos de emancipação política, contudo apresenta um histórico de formação populacional construído a partir dos povos nativos (indígenas) e da migração de pessoas de outros estados e países. A diversidade de gêneros e programas radiofônicos despertam a reflexão sobre a conexão entre local, regional e global, visto que o município com pouco mais de 220 mil habitantes tem como principal atividade econômica, a produção agropecuária.

Por outro lado, a expansão na atividade primária atraiu agroindústrias estrangeiras, com unidades estabelecidas no município e que processam a matéria-prima, exportada para outros estados e países. A fim de se conseguir mão-de-obra capacitada foram criadas cinco instituições de ensino superior, além do trânsito constante de profissionais que frequentam o município, em função do trabalho. O contexto regional traçado colabora com os resultados do levantamento apresentado, no qual foram identificados conteúdos com 
ênfase no entretenimento que visam atender a demanda dos moradores (música e religião).

Os resultados colaboram ainda, com os debates desenvolvidos em diferentes regiões brasileiras, sobre o espaço do rádio e do radiojornalismo desenvolvido no atual cenário tecnológico. Contudo, observa-se no objeto de estudo, a presença marcante da identidade local e regional, o que na análise da pesquisadora, Cicília Peruzzo (2003), precisa ser observado para além das fronteiras territoriais ou geográficas.

Com o advento das novas tecnologias de comunicação, principalmente da internet, há um rompimento da noção de território geográfico como sendo determinante do local e do comunitário. As dimensões de familiaridade (língua, valores, tradições, religião etc.) podem ser partilhadas independente do espaço territorial. As relações podem se estabelecer, com base da proximidade de interesses e identificações, através de comunidades virtuais. (PERUZZO, 2003, p. 68).

Nesse sentido, o local e o regional não podem ser avaliados separadamente, visto que existem elementos culturais, sociais, políticos e econômicos que os interconectam (PERUZZO, 2003) e incluem ainda, as perspectivas nacional e global.

Colaboração oportuna sobre a reorganização espacial da comunicação no âmbito do rádio é feita por Bonixe (2012, p. 18) ao argumentar que as rádios locais funcionam como um meio de proximidade entre a população e 0 ambiente no qual está inserida. Isso, por levar as notícias do mundo aos ouvintes e por funcionarem como espaços da memória coletiva de uma comunidade. "Os veículos regionais migraram para a internet, a fim de aproveitar as ferramentas interativas e participarem dos espaços de debate público e conhecimento dos assuntos locais".

\section{Surgimento do rádio em Dourados}

O município de Dourados está localizado a $235 \mathrm{~km}$ de Campo Grande, capital de Mato Grosso do Sul, na região Centro-Sul do Estado. Conforme 


\section{ÂNEORA}

Daniela Cristiane OTA - Aline de Oliveira SILVA

levantamento divulgado pelo IBGE em 2018, conta com uma população de 220.965 pessoas, sendo considerada a segunda cidade mais populosa de 79 que constituem a unidade federativa, além de ser responsável pelo $3^{\circ}$ Produto Interno Bruto (PIB) estadual. Com 84 anos de emancipação, a localidade teve a formação sócio territorial marcada pela chegada de imigrantes nos séculos XIX e XX.

Contudo, conforme detalha o pesquisador Jaime Ribeiro de Santana Júnior (2009), as terras da região foram inicialmente habitadas por índios Guaranis e Kaiowás, além de ex-combatentes da Guerra do Paraguai, no período compreendido entre 1864 e 1870. No entendimento do autor, em Mato Grosso do Sul, a história agrícola está ligada diretamente ao processo de colonização, impulsionado pelas políticas públicas na administração do expresidente do Brasil, Getúlio Vargas, no período do Estado Novo (1937-1945).

As ações implantadas no Sul de Mato Grosso tinham objetivo de estimular a vinda de pessoas e famílias de outros estados para povoar as áreas mais desertas e próximas da fronteira com o Paraguai.

O processo de colonização esteve atrelado a diretrizes governamentais, com incentivos à produção agrícola, através da distribuição de terras gratuitas, visando o aumento da oferta de alimentos. Nesse sentido, pretendia-se desenvolver regiões urbanas e industriais, para qual, tornava-se necessário integrar o interior do país à economia nacional. Almejava-se povoar imensas áreas pouco ocupadas do território nacional e, sobretudo, temia-se que as áreas de fronteira fossem apoderadas por outros países (SANTANA JÚNIOR, 2009, p. 92).

Diante desse cenário, a criação da colônia agrícola federal efetivada na década de 1940, com capacidade para instalar dez mil famílias em trezentos mil hectares, impulsionou o aumento da população e da produção agropecuária. Duas décadas depois (1960) é registrado um novo salto populacional, e conforme informações de Gressler e Swensson (1988), aconteceu em função da chegada de agricultores da região Sul do País, especificamente, do Rio Grande do Sul. Outros grupos que se estabeleceram 
no município foram famílias japonesas, nordestinas, mineiras, paulistas e do Paraguai.

A consequência natural do aumento populacional foi a ampliação desordenada do perímetro urbano dificultando assim, o planejamento estrutural por parte do poder público. Entretanto, na avaliação dos pesquisadores, o fato mais marcante na formação de Dourados decorreu pela criação de uma rede de relações terciárias, representadas principalmente por empresas ligadas ao setor agropecuário, instituições estaduais e federais de administração, sucursais bancárias, faculdades e universidades. "Dourados passa a comandar os desígnios de uma imensa região, cujos municípios não foram capazes de resolver os problemas comuns, gerados pelas mudanças agrícolas". (GRESSLER; SWENSSON, 1988, p. 106).

A pesquisadora Suzana Arakaki (2003) desenvolveu um trabalho histórico sobre a criação do município com foco nas questões políticas e sociais, visto que o recorte da pesquisa foi o período de 1964 quando inicia a Ditadura Militar em todo País. Assim como outros autores elencados, destaca que a implantação da Colônia Agrícola Nacional de Dourados (CAND) impulsionou a cidade na perspectiva econômica e política. "Da densa e heterogênea população surgiram forças representativas, agregadas em partidos políticos, os quais durante a década de 1960 tiveram papéis decisivos na história local". (ARAKAKI, 2003, p. 41).

Gressler e Swensson (1988) relatam que as linhas telegráficas implantadas no antigo estado do Mato Grosso datam do período entre 1900 e 1905, por intermédio da missão de Cândido Mariano da Silva Rondon que foi designado para chefiar a Comissão de Linhas Telegráficas Estratégicas de Mato Grosso ao Amazonas.

Em 1902, Rondon fez a exploração do Rio Taquari, se deslocou para Aquidauana e depois para Corumbá, Miranda e Nioaque. Depois de três anos (1905) chegou a Porto Murtinho aonde foi instalado o ramal São Carlos, na 


\section{ANCORA}

Daniela Cristiane OTA - Aline de Oliveira SILVA

divisa com o Paraguai, o qual seria estendido para Ponta Porã, Dourados e Campo Grande, alguns anos depois. Observa-se aqui uma lacuna expressiva entre o período das instalações telegráficas e o início das atividades radiofônicas na região, que somaram quase meio século.

A primeira emissora de rádio em atividade no município de Dourados foi a Rádio Clube Dourados, que começou a transmitir em 1955. O jornalista e docente em comunicação, Osni Tadeu Dias (2005) esclarece que oficialmente, o veículo recebeu a homologação do Ministério da Educação e do Departamento Nacional de Telecomunicações (Dentel), em 1957, passando a operar com o prefixo ZYX 23. "O rádio beneficiou a população que sofria com a precariedade das estradas e distanciamento das ferrovias, levando a informação aos mais longínquos rincões". (DIAS, 2005, p. 05).

Semelhante a outras localidaes do Estado, os empresários que investiram na criação e construção de veículos de comunicação no município tinham forte relacionamento político. No caso da Rádio Clube, os primeiros proprietários foram os irmãos Brunini, que contrataram o jornalista paulista, Flávio Araújo para ser o diretor da emissora. Em 1962, a rádio foi vendida para Antônio Moraes dos Santos e Rachid Saldanha Derzi, e em 1963, Jorge Antônio Salomão adquire a rádio em sociedade com Derzi (na época deputado federal), dando início ao gerenciamento e profissionalização do veículo em atividade até os dias atuais.

A pesquisa realizada por Dias (2005) conta com riqueza de detalhes as etapas do desenvolvimento da emissora, as quais foram fundamentais para conhecer os primórdios do veículo localizado em Dourados. O pesquisador pontua fatores importantes na trajetória da Rádio Clube, entre eles a diversidade de programas idealizados pelos radialistas, apesar da precariedade estrutural.

Programas de auditório como o 'Programa de Calouros' e o 'Domingo Alegre da Criança Feliz', além dos musicais, 'Recuerdos Del Paraguay', 'Alvorada 
Sertaneja', 'O Tango e a Seresta' e 'Roda de Violeiros' marcaram época e são lembrados ainda hoje pelos moradores. Foi observado ainda que o programa mais antigo da emissora é o "Mini Recados", um serviço de utilidade pública que tem grande participação dos ouvintes. "Atualmente, o programa anuncia desde telefones celulares até documentos perdidos e funciona também como um Balcão de Empregos, sendo um serviço gratuito". (DIAS, 2005, p. 14).

\section{Mudança de cenário e consumo midiático}

Em pouco mais de meio século desde a transmissão da primeira emissora de rádio no município de Dourados, o cenário se modificou expressivamente e de acordo com levantamento realizado em fevereiro de 2020, a quantidade de veículos em funcionamento somou 46, dos quais 11 operam no formato de Amplitude Modulada (AM), Frequência Modulada (FM), contra 35 Web Rádios.

A plataforma utilizada para aferição foi o site Rádios.com em atividade desde 1997, o qual hospeda rádios online de todo Brasil. Conforme informado pela empresa, a média de visitas únicas diárias é de 130 mil, além de disponibilizar o aplicativo RadiosNet para download via Android e IOS. Outra informação disponibilizada na plataforma é o número de acessos mensal. No total de emissoras identificadas foram contabilizadas 104.287 visitas únicas (individuais com mais de dois minutos de permanência no site da emissora).

A fim de realizar uma melhor distinção dos formatos encontrados na pesquisa buscou-se subsídio teórico na obra 'Gêneros Radiofônicos' de André Barbosa Filho (2009). No trabalho acadêmico, o pesquisador reforça a atenção que deve ser dada nas diferenciações conceituais ligada ao veículo.

Termos como gênero e formato radiofônico, programa de rádio, programação radiofônica e produtos radiofônicos são confundidos e utilizados muitas vezes como sinônimos, sem que haja concordância quanto aos seus significados particulares. [...]. Importante esclarecimento deve ser realizado sobre este trânsito conceitual, tendo em vista a demarcação de fronteiras e suas devidas posições no universo da produção sonora. (BARBOSA FILHO, 2009, p. 71)

João Pessoa - Brasil | ANO 7 VOL.7 N.1 | JAN./JUN. 2020 | p. 263-279 


\section{ÂNCORA}

Daniela Cristiane OTA - Aline de Oliveira SILVA

Nesse sentido, os gêneros identificados foram: jornalístico, de entretenimento e publicitário, conforme detalhados a seguir. Do total de emissoras catalogadas, três se denominam como comunitárias (música e religião), duas jornalísticas, 10 ecléticas (música, utilidade pública e notas jornalísticas), além de oito com conteúdo voltado exclusivamente para música, uma focada em esportes e 13 para programação religiosa.

As emissoras elencadas no gênero jornalístico compreendem os veículos categorizados na pesquisa como jornalísticos, esportivos e ecléticos. Nos três são identificados os seguintes formatos: nota, notícia, boletim, reportagem, entrevista, comentário, programa esportivo e temático.

Os veículos com conteúdo exclusivo em música adotam o gênero de entretenimento, os quais, segundo Barbosa Filho (2009, p. 115) "se caracterizam por ter a capacidade de se combinar com outros formatos ou gêneros, e ainda servir de ferramenta para a informação, anúncio, prestação de serviço e educação".

O maior número de rádios digitais é de cunho exclusivamente religioso, sendo: nove neopentecostais (protestantes), duas espiritistas e uma católica. Aqui o gênero equivalente é o publicitário, tendo em vista a utilização do espaço radiofônico para divulgação e venda de produtos e serviços. Junto com esportes, jingles, programas institucionais, eleitorais está o programa religioso que desenvolve um conteúdo semelhante aos programas produzidos por organizações públicas.

\section{Considerações Finais}

A pesquisa divulgada no presente artigo teve como objetivo dar continuidade a uma etapa do estudo iniciado em 2019, por ocasião do projeto de dissertação de mestrado de uma das autoras, o qual teve como objeto de estudo, o radiojornalismo rural na cidade de Dourados. Além da compreensão sobre a importância de aprofundar os estudos sobre rádio no estado de Mato 
Grosso do Sul, a escolha do município foi definida em razão de sua relevância territorial, social e econômica.

Com a identificação da quantidade de web rádios em atividade no município percebeu-se a mudança expressiva na dinâmica de consumo midiático voltada ao veículo rádio, em uma localidade distante dos grandes centros urbanos, mas que possui uma posição territorial estratégica no estado de Mato Grosso do Sul e na fronteira com o Paraguai.

Com esse recorte pode-se verificar que o ouvinte de rádio de Dourados é heterogêneo em termos de faixa etária, classe econômica e escolaridade, por exemplo. Esses fatores ampliam oportunidades para pesquisas futuras, sob a perspectiva da recepção e audiência.

Entretanto, os resultados observados na atual etapa da pesquisa demonstraram que a preferência do público local em acessar a rádios digitais está ligada diretamente aos aspectos socioculturais elencados sobre o município. O trânsito de pessoas que circulam em Dourados e a pluralidade de negócios realizados na região desencadeiam a procura por acesso a informações ou entretenimento, viabilizados pela facilidade do acesso ao ambiente virtual.

A partir da preferência de programação observada nas rádios digitais é possível confirmar que o surgimento dos veículos é recente e formatado a partir da demanda da população local, mais interessada em consumir conteúdo de entretenimento segmentado e que esteja ligada ao seu cotidiano local. 0 indicativo positivo é observado na transmissão de dois canais focados no radiojornalismo, os quais podem colaborar para o desenvolvimento de programações alinhadas com o interesse informativo dos ouvintes.

Outra observação que se faz necessária é de que os veículos tradicionais precisam se adaptar ao atual cenário das plataformas digitais, a fim de que consigam manter seus negócios, seja na imprensa ou no mercado de entretenimento. Uma reflexão que pode resumir o atual momento do rádio 


\section{ÂNEORA}

Daniela Cristiane OTA - Aline de Oliveira SILVA

vem do pesquisador Armand Balsebre que durante conferência realizada no Radio Evolution Congress, em 2011, considerou algumas condições para que o rádio pudesse se transformar em uma nova mídia:

Se o rádio souber como chegar a ser uma das melhores plataformas para transmissão da arte sonora, um dos melhores canais para comunicação pública, para o relato da atualidade e ainda souber como investir mais dinheiro em conteúdo, em lugar de tecnologia...poderá então ser um novo meio sonoro, da nova "sonosfera", para os novos radiouvintes, em qualquer contexto tecnológico de reprodução sonora. (BALSEBRE, 2013, p. 16).

Em um século de história o veículo que passou por tantas transformações e adaptações demonstra que é possível se reinventar, mas, daqui para frente sob a perspectiva de um público mais exigente e que demonstra interesse em interagir e participar da construção da programação.

\section{Referências}

ARAKAKI, Suzana. Dourados: memórias e representações de 1964.

Dourados: Universidade Federal de Mato Grosso do Sul - UFMS, 2003. 148 p. (Dissertação de Mestrado em História) - Universidade Federal de Mato Grosso do Sul, Dourados, 2003.

BALSEBRE, Armand. O Rádio está morto...Viva o Som! ou como o rádio pode se transformar em uma nova mídia. Revista Significação, São Paulo, v.40, no 39, p.14-23, 2013. DOI https://doi.org/10.11606/issn.2316-

7114.sig.2013.59946. Disponível em:

<http://www.revistas.usp.br/significacao/article/view/59946> Acesso em: 18 fev. 2020.

BARBOSA FILHO, André. Gêneros Radiofônicos. 2. Ed. São Paulo: Paulinas, 2009.

BONIXE, Luis. In: Jornalismo de Proximidade: Limites, Desafios e Oportunidades. CORREIA, C. João (org). LabCom Books, p.17-30, Portugal, 2012. Disponível em: <https://www.labcom-ifp.ubi.pt/ficheiros/20121224agora_ebook.pdf> Acesso em: 14 fev. 2020.

DIAS,T. Osni. Rádio Clube de Dourados: 50 anos de história. Interletras Dourados, v.01, no 01, 2005. Disponível em:

$<$ https://document.onl/documents/radio-clube-de-dourados-50-anos-dehistoria-osni-1949-surgiu-a-radio-am.html> Acesso em: $18 \mathrm{fev} .2020$. FERRARETO, Luiz Arthur. Rádio: teoria e prática. 1. ed. São Paulo: Summus, 2014. 272 p.

GRESSLER, L. Alice; SWENSSON, J. Lauro. Aspectos Históricos do povoamento e da colonização do estado de Mato Grosso do Sul: 
destaque especial ao município de Dourados. Dourados, MS: 1988, CDD981.71-981.712.

HAUSSEN, Dóris Fagundes. Rádio brasileiro: uma história de cultura, política e integração. Barbosa Filho; Piovesan; Beneton, (org). Rádio - Sintonia do futuro. São Paulo: Paulinas, 2004, p. 51-62.

ITINOSI, S. Luciana. Rádio na Internet: concessão para quê? Trabalho de Conclusão de Curso, São Paulo, Escola de Comunicações e Artes da Universidade de São Paulo, 1997.

KISCHINHEVSKY, Marcelo. Rádio e Mídias sociais: mediações e interações radiofônicas em plataformas digitais de comunicação. 1. ed. Rio de Janeiro:

Editora Mauad X, 2016. 143 p.

KUHN, Fernando. O Radio Na Internet: rumo a quarta mídia. 2000. 126 p. Dissertação (Mestrado em multimeios) - Instituto de Artes, Universidade Estadual de Campinas, 2000.

MEDITSCH, Eduardo. (org). Rádio e Pânico 2: A Guerra dos Mundos, 75 anos depois. 1. ed. Florianópolis: Insular, 2013. 264 p.

MEDITSCH, Eduardo. 0 rádio na era da Informação. Teoria e Técnica do novo Radiojornalismo. 2. ed. Florianópolis: Insular, 2007. 300 p.

MOREIRA, Sonia Virginia. 70 anos de Radiojornalismo no Brasil (19412011). 1. ed. Rio de Janeiro, Eduerj, 2011. 384 p.

MOREIRA, Sonia Virginia.; BIANCO, Nelia Del (org). Desafios do rádio no século XXI. 1. ed. Rio de Janeiro: Eduerj, 2001. 250 p.

ORTRIWANO, Gisela Swetlana. A informação no rádio: os grupos de poder e a determinação dos conteúdos. 1. ed. São Paulo: Summus, 1985. $124 \mathrm{p}$.

PERUZZO, K. M. Cicilia. Mídia Local, uma mídia de proximidade.

Comunicação Veredas. Revista do Programa de Pós-graduação em Comunicação. Marilia, v.1, no 02, p.65-89, 2002. Disponível em:

<https://www.unimar.br/biblioteca/publicacoes/comunicacao05.pdf>. Acesso em: 15 fev. 2020

Rádio Grande 92.1 FM. Disponível em:

http://www.grandefm.com.br/Dourados. Acesso em: 28 fev. 2020

Radios.com. Disponível em: <https://www.radios.com.br/aovivo/radiogrande-921-fm/13334>. Acesso em: 28 fev. 2020

SAMPAIO, Walter. Jornalismo Audiovisual: Teoria e Prática do Jornalismo no Rádio, na TV e no Cinema. 1. ed. Petrópolis: Vozes,1971. 118 p.

TRIGO-DE-SOUZA, M. Ligia. Rádios.Internet.br: o rádio que caiu na rede.

Revista USP - 80 anos de Rádio, São Paulo, v. 56, p. 92-99, 2003.

Disponível em:

<http://www.revistas.usp.br/revusp/article/view/33810/36548>. Acesso em:

15 fev. 2020.

João Pessoa - Brasil | ANO 7 VOL.7 N.1 | JAN./JUN. 2020 | p. 263-279 